\title{
Comparison of Three Cough-Augmentation Techniques in Neuromuscular Patients: Mechanical Insufflation Combined with Manually Assisted Cough, Insufflation-Exsufflation Alone and Insufflation-Exsufflation Combined with Manually Assisted Cough
}

\author{
Matthieu Lacombe Lorena Del Amo Castrillo Aurélien Boré David Chapeau \\ Eric Horvat Isabelle Vaugier Michelle Lejaille David Orlikowski \\ Hélène Prigent Frédéric Lofaso \\ Réanimation Médicale, Physiologie - Explorations Fonctionnelles, Centre d'Innovations Technologiques UMR \\ 805, Hôpital Raymond Poincaré, AP-HP, Garches, and EA 4497, Université de Versailles Saint-Quentin-en-Yvelines, \\ Versailles, France
}

\section{Key Words}

Cough · Mechanical insufflation-exsufflation .

Neuromuscular diseases · Intermittent positive-pressure breathing $\cdot$ Respiratory failure

\footnotetext{
Abstract

Background: Mechanical insufflation-exsufflation (MI-E), more commonly known as 'cough assist therapy', is a method which produces inspiratory and expiratory assistance to improve cough performances. However, other alternatives or combinations are possible. Objective: The objective was to compare the effects of mechanical insufflation combined with manually assisted coughing (MAC), insufflation-exsufflation alone and insufflation-exsufflation combined with MAC in neuromuscular patients requiring cough assistance. Methods: Eighteen neuromuscular patients with severe respiratory muscle dysfunction and peak cough flow (PCF) lower than 3 liters/s or maximal expiratory pressure (MEP)
}

lower than $+45 \mathrm{~cm} \mathrm{H}_{2} \mathrm{O}$ were studied. Patients were studied under three cough-assisted conditions, which were used in random order: insufflation by intermittent positive-pressure breathing (IPPB) combined with MAC, MI-E and MI-E + MAC. Results: Overall, PCF was higher with IPPB + MAC than with $\mathrm{MI}-\mathrm{E}+\mathrm{MAC}$ or MI-E alone. Among the 12 patients who had higher PCF values with IPPB + MAC than with the two other techniques, 9 exhibited mask pressure swings during MI-E exsufflation, with a transient positive-pressure value due to the expiratory flow produced by the combined patient cough effort and MAC. Each of these 9 patients had higher PCF values ( $>5$ liters/s) than did the other 9 patients when using IPPB + MAC. Conclusion: Our results indicate that adding the MI-E device to MAC is unhelpful in patients whose PCF with an insufflation technique and MAC exceeds 5 liters/s. This is because the expiratory flow produced by the patient's effort and MAC transitorily exceeds the vacuum capacity of the MI-E device, which therefore becomes a transient load against the PCF.

\section{KARGER}

E-Mail karger@karger.com www.karger.com/res
(C) 2014 S. Karger AG, Basel

0025-7931/14/0883-0215\$39.50/0
Prof. Frédéric Lofaso

Services de Physiologie et Explorations Fonctionnelles

Hôpital Raymond Poincaré, AP-HP

FR-92380 Garches (France)

E-mail f.lofaso@ rpc.aphp.fr 


\section{Introduction}

Poor cough efficiency resulting in an inability to clear the airways of secretions is a major risk factor for acute respiratory failure in patients with neuromuscular disease (NMD) [1]. It may also impair successful weaning from invasive ventilation $[2,3]$. Peak cough flow (PCF) is widely considered to predict cough efficiency $[4,5]$ and when PCF is equal to or less than 4.5 liters/s, in a medically stable patient, it is recommended to introduce methods for assisted airway clearance to prevent pneumonia, atelectasis and respiratory failure [6].

Cough-assistance methods include techniques that provide inspiratory and/or expiratory assistance to improve cough efficiency [7]. Inspiratory assistance techniques increase the inspired volume during the first phase of the cough. Inspiratory capacity (IC) can be increased by glossopharyngeal breathing, as first described in 1951 by Dail [8]. This method requires functional integrity of the larynx, which acts as a valve [9]. IC can also be increased by the air stacking technique, in which the patient takes two or more insufflations from a ventilator without exhaling between them [10]. Air stacking requires a competent glottis and ventilation via a volumetric mode. One limit is the poor adjustment of the total volume insufflated according to the tolerance. Insufflation using a manual resuscitation bag seems more efficient than air stacking when bulbar muscles are weak [11]. Pressuretargeted modes such as pressure-support ventilation can be used $[12,13]$, but generally produce maximal pressures lower than $40 \mathrm{~cm} \mathrm{H}_{2} \mathrm{O}$. Finally, another alternative is intermittent positive-pressure breathing (IPPB) [14-17], which delivers a constant inspiratory flow until a targeted pressure is reached. Regardless of the technique used, increasing IC significantly improves PCF compared to coughing without inspiratory assistance $[7,10,11,13,16$, $18-21]$.

Additionally to inspiratory assistance, two expiratoryassistance techniques are widely used, either separately or together. The oldest and most widely used is manually assisted coughing (MAC) [5], in which manual thoracic and/or abdominal pressure is applied by a caregiver during cough. MAC increases air compression in the lungs, thereby improving cough performance $[7,13,16$, $18,20,22]$. The other technique is mechanical exsufflation using a device that both insufflates and exsufflates the lungs (mechanical insufflation-exsufflation; MI-E). This device was first marketed in the 1950s and then brought back to the attention of clinicians in the 1990s by Bach [7].
Studies have compared these two expiratory-assistance techniques used in combination with inspiratory assistance. In NMD patients, Bach [7] found that MI-E was more effective than MAC. In patients with amyotrophic lateral sclerosis, MI-E seemed unhelpful when the PCF achieved with inspiratory assistance and MAC was greater than 4 liters/s, but the patients did not cough actively [19]. In a similar population, coughing with active patient participation was not significantly different between MI-E and MAC [21]. The purpose of this study in NMD patients was to compare PCF using three techniques that combine inspiratory and expiratory support: IPPB + MAC, MI-E and MI-E + MAC.

\section{Material and Methods}

\section{Patients}

The study was performed between March 2012 and June 2013 at the home ventilation unit of the medical intensive care unit of the Raymond Poincaré Teaching Hospital, Garches, France. We used a randomized (block size of 6), open, single-center, crossover design to compare three cough-assist techniques that compensated both inspiratory and expiratory muscle weakness: IPPB + MAC, MI-E and MI-E + MAC.

The study was approved by the hospital's ethics committee and registered on ClinicalTrials.gov (No. NCT 01518439). Eighteen NMD patients were recruited during their annual follow-up visits in the postintensive care unit, which routinely included patient education about cough-assist techniques. At each visit, the following were recorded routinely: vital capacity [23], unassisted PCF [23], maximum expiratory pressure (MEP), maximum inspiratory pressure (MIP), and sniff test measurements [16, 24]. Vital capacity and PCF were measured with the same device and by the same technician (M.Le.) as during the trial described below.

Inclusion criteria were documented NMD, inexperience of cough-assist technique, age $>18$ years, hemodynamic stability, absence of acute bronchial congestion (respiratory tract infection) in the past month, presence of noninvasive ventilation and PCF lower than 3 liters/s (which was more severe than recommended [6] but was the threshold for statutory healthcare insurance coverage in France and Belgium) [20], or MEP lower than $+45 \mathrm{~cm} \mathrm{H}_{2} \mathrm{O}$ [25]. Patients gave written informed consent before being included in the study.

\section{Training Sessions and Settings}

The day before testing, the patients were familiarized with the study cough-assist techniques and the settings of the assistance device and type of manual pressure (thoracic and/or abdominal) were determined.

For the IPPB + MAC condition, insufflation was provided by an Alpha $200 \mathrm{C}$ ventilator (Air Liquide, Antony, France). Patients started IPPB insufflation with an inspiratory effort then allowed the insufflation to continue passively until the selected inspiratory pressure was reached, in about $5 \mathrm{~s}$. The lowest inspiratory trigger was chosen to facilitate the beginning of insufflation. The inspira- 
tory pressure was increased gradually to the highest tolerated value or $40 \mathrm{~cm} \mathrm{H}_{2} \mathrm{O}$. Inspiratory flow was set to maximize patient comfort. Once the inspiratory pressure was reached, a physiotherapist removed the IPPB circuit to avoid resistance while coughing. At the same time, MAC was performed by a second physiotherapist who applied manual pressure to the patient's thorax and/or abdomen during exsufflation while encouraging the patient to cough. The site and direction of manual pressures were determined based on patient comfort and on cough efficiency as perceived by the patient and physiotherapist.

The MI-E condition was achieved using the CoughAssist device (JH Emerson Co., Cambridge, Mass., USA) in manual mode. After each insufflation, a physiotherapist delivered the exsufflation while simultaneously asking the patient to cough. Inspiratory and expiratory pressures were increased/decreased gradually to the highest/lowest tolerated values, up to $+40 \mathrm{~cm} \mathrm{H}_{2} \mathrm{O}$ for inspiratory pressure and down to $-40 \mathrm{~cm} \mathrm{H}_{2} \mathrm{O}$ for expiratory pressure. Insufflation flow adjustment (high or low insufflation flow) was set according to patient comfort.

For the MI-E + MAC condition, MI-E was delivered as described above and MAC was performed as described during MAC + IPPB. IPPB and MI-E were applied using a facemask (Ambu UltraSeal, Ambu, Bordeaux, France), chosen to fit each of the patients individually.

\section{Outcomes and Measurements}

As previously proposed in the literature [26], PCF was the primary outcome measure. The secondary outcome measures were effective cough time (ECT), defined as the time with PCF above 3 liters/s, IC and subjective parameters (breathing comfort and cough effectiveness as perceived by patient).

Flow was measured using a Fleisch No. 4 pneumotachograph (Fleisch, Lausanne, Switzerland), which was linear above 10 liters/s. Accordingly, the volume measured during calibration with a syringe was not influenced by a range flow varying between 0.5 and 12 liters/s. Mask pressure (Paw) was measured using a differential pressure transducer ( $\mathrm{MP} 45 \pm 100 \mathrm{~cm} \mathrm{H}_{2} \mathrm{O}$; Validyne Engineering Corp., Northridge, Calif., USA). Flow and mask pressure signals were sampled at $1,000 \mathrm{~Hz}$ and recorded using an analogic-numeric system (MP100, Biopac System, Goleta, Calif., USA) and its software (Acknowledge). Throughout the tests, oxygen saturation and heart rate were monitored using pulse oximetry.

\section{Study Protocol}

All measurements were performed with the patient seated in his or her wheelchair. Three physiotherapists (M.La., L.D.A.C. and A.B.) carried out the trials. For each patient, two physiotherapists were needed: one for using the device and one for MAC manoeuvers. The same physiotherapist performed the different cough techniques for a single patient. In addition, the same technician (M.Le.) performed the measurements. Great care was taken to avoid leaks around the mask during each technique, which was performed using the settings as determined during the training sessions. The physiotherapists stimulated the patient's efforts to cough via strong verbal encouragement. For IPPB + MAC, measurements were obtained during coughing after the patient was disconnected from the IPPB at the end of the insufflation (to avoid resistance). Patients could rest between each coughing session, and total patient participation did not exceed $2 \mathrm{~h}$. To avoid bias, the three cough-assist techniques were tested in random order. In addition, care was taken to use the circuits recommended by the manufacturers. To avoid altering device performance, circuit length was decreased in order to maintain the same resistance when including the measurement circuitry between the patient and the device.

Each test was repeated at least three times [27], and the highest PCF value was selected if the difference did not exceed $10 \%$ of the other two values. IC, PCF and time with PCF above 3 liters/s ECT were measured for each cough-assist technique. In addition, breathing comfort was evaluated by the patients using a visual analogue scale [28] ranging from 0 ('I breathe very badly') to 10 ('I breathe very well'). Cough effectiveness as perceived by the patient was also rated on a 10-point visual analogue scale (from 0 , 'completely inefficient cough', to 10, 'fully effective cough').

\section{Statistical Analysis}

Friedman tests were used for global comparisons of the coughassist techniques. In the case of a significant difference, pairwise comparisons were performed using Wilcoxon's test. When necessary, linear regression analysis was used to evaluate correlations between two values. Values of $\mathrm{p} \leq 0.05$ were considered significant.

\section{Results}

\section{Population}

Table 1 lists the main characteristics of the 18 consecutive patients included during the study period. Patient 4 had an inclusion criterion upon admission (MEP $<45 \mathrm{~cm}$ $\mathrm{H}_{2} \mathrm{O}$ ) which was not confirmed afterwards (table 1).

\section{Global Analysis}

Though inspiratory pressure was higher with IPPB than MI-E (table 1 ; mean \pm SD difference $=3.4 \pm 4.9 \mathrm{~cm}$ $\mathrm{H}_{2} \mathrm{O}$, Wilcoxon $\mathrm{p}=0.018$ ) IC increased similarly with the three techniques (fig. 1), while the physiotherapists perceived insufflation as more passive with the use of IPPB than MI-E. PCF values are presented in figure 2 and, as outlined in the figure, each condition was significantly different from the others, including the baseline condition (Friedman and Wilcoxon tests). PCF was highest with IPPB + MAC, followed by MI-E + MAC (Wilcoxon $\mathrm{p}=0.0108$ ), which was higher than with MI-E alone (Wilcoxon $\mathrm{p}=0.0297)$, which was higher than the baseline condition (Wilcoxon $\mathrm{p}=0.003$ ).

ECT improved significantly with all three techniques. The ECT increase was smaller with MI-E alone than with the two techniques that included MAC (fig. 3). ECT was not significantly different between these last two techniques.

Comfort ratings were similar with all techniques (table 2). In contrast, subjective cough effectiveness was rat- 
Table 1. Characteristics of the 18 patients with neuromuscular disorders and chronic respiratory failure

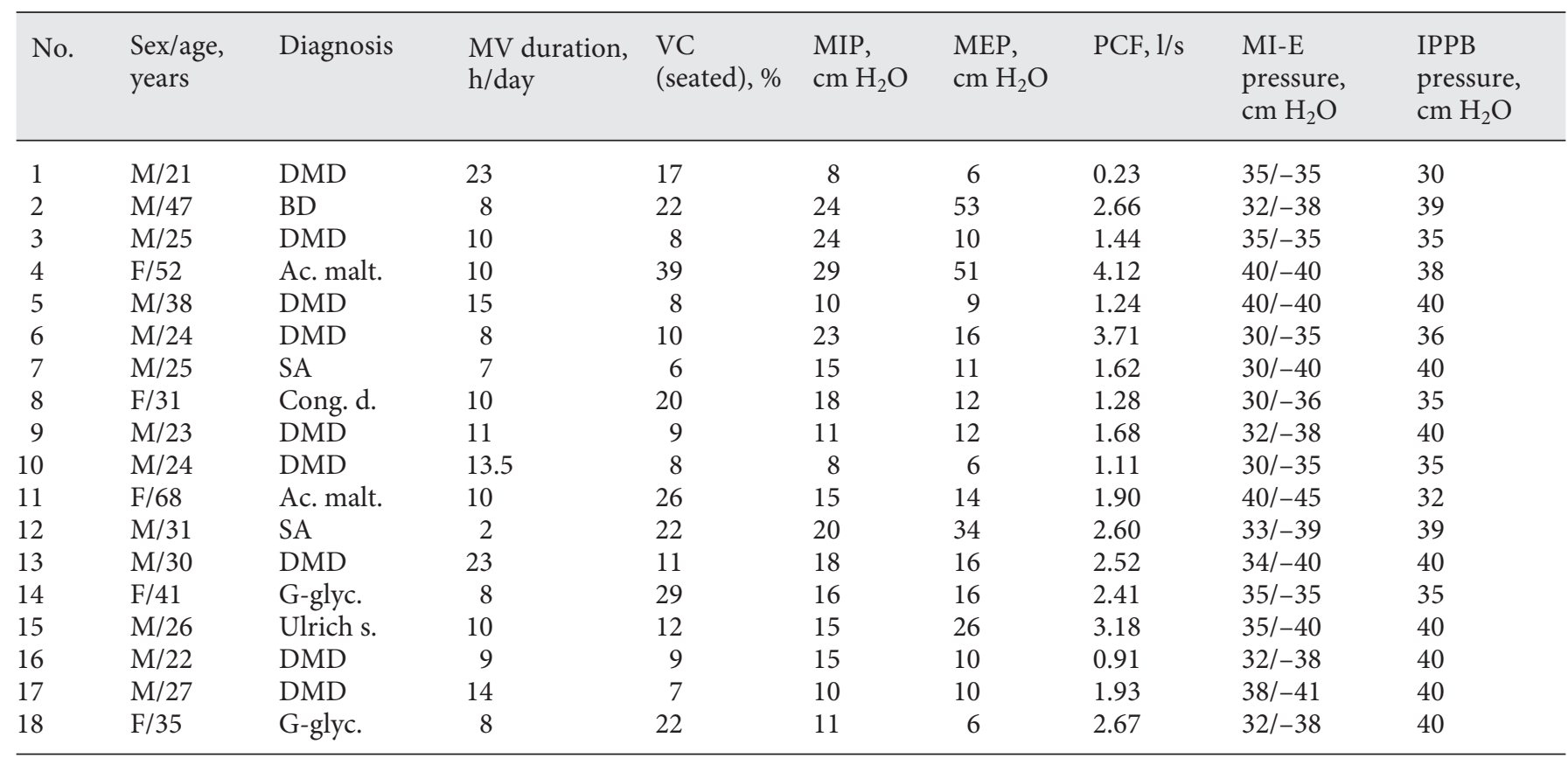

MV = Mechanical ventilation; $F$ = female; $M=$ male; $V C=$ vital capacity; Ac. malt. = acid maltase deficiency; DMD = Duchenne's muscular dystrophy; Cong. d. = congenital muscular dystrophy; G-glyc. = gamma-sarcoglycanopathy; BD = Becker's muscular dystrophy; SA = spinal amyotrophy; Ulrich s. = Ulrich syndrome.

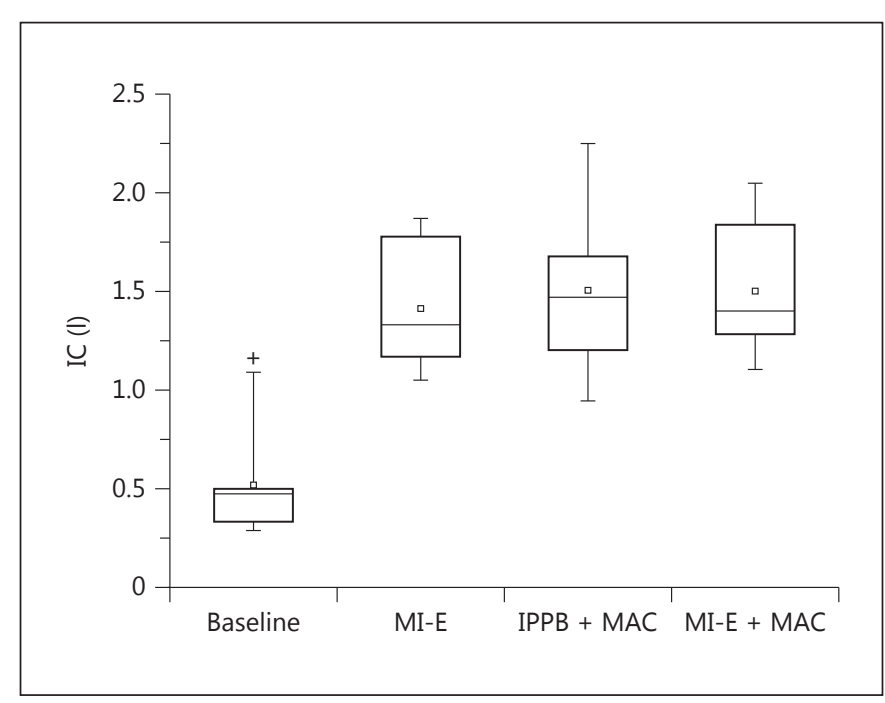

Fig. 1. IC at baseline and with the three cough-assist techniques: MI-E, IPPB + MAC and MI-E + MAC. The boxplots indicate the 25 th percentile, the median and the 75 th percentile, and the whiskers indicate the 5 th and 95 th percentiles. Means are represented by small squares. Friedman test, $\mathrm{p}<0.0001 .{ }^{+}$Different from the other conditions, Wilcoxon test.

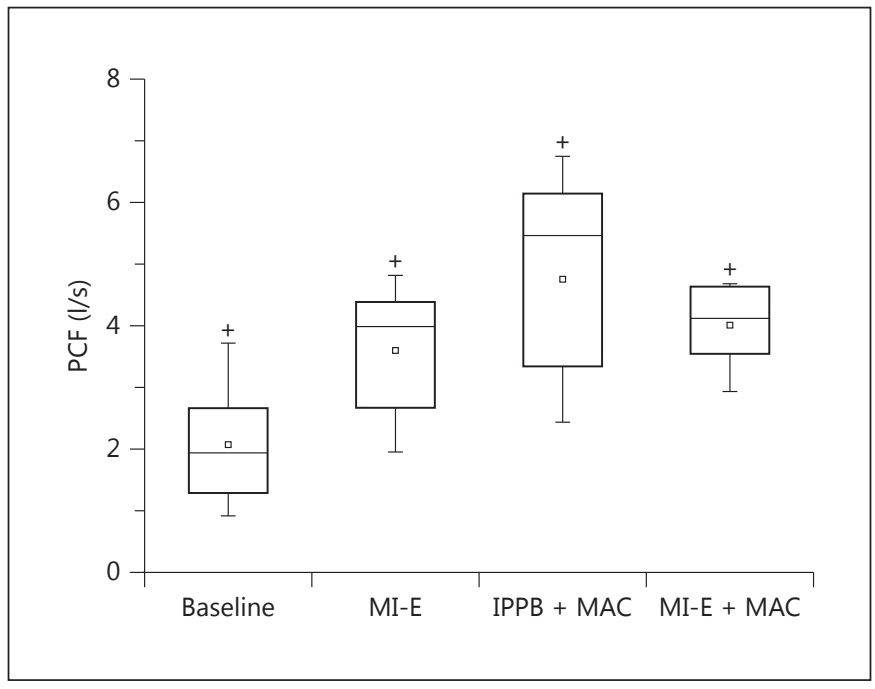

Fig. 2. PCF at baseline and with the three cough-assist techniques: MI-E, IPPB + MAC and MI-E + MAC. The boxplots indicate the 25 th percentile, the median and the 75 th percentile, and the whiskers indicate the 5 th and 95 th percentiles. Means are represented by small squares. Friedman test, $\mathrm{p}<0.0002 .{ }^{+}$Different from the other conditions, Wilcoxon test. 
Table 2. Subjective evaluations of breathing comfort and cough effectiveness by the patients on $0-10$ visual analogue scales

\begin{tabular}{llll}
\hline & MI-E & IPPB + MAC & MI-E + MAC \\
\hline Comfort & $6.4(5.5-7.0)$ & $7.0(6.0-8.5)$ & $6.6(5.8-8.0)$ \\
Effectiveness & $6.4(4.8-8.2)$ & $8.3(7.2-9.0)^{*}$ & $8.5(6.2-9.0)^{*}$ \\
\hline
\end{tabular}

Data are medians with 25 th and 75 th percentiles in parentheses. ${ }^{*} \mathrm{p}<0.05$ compared to MI-E (Wilcoxon test).

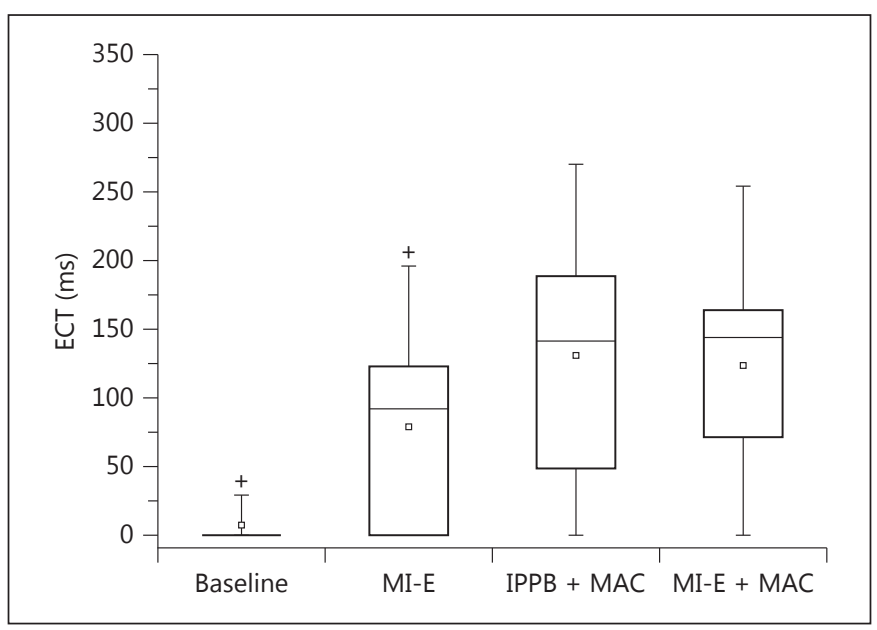

Fig. 3. ECT (time spent with PCF greater than 3 liters/s) at baseline and with the three cough-assist techniques: MI-E, IPPB + MAC and MI-E + MAC. The boxplots indicate the 25th percentile, the median and the 75th percentile, and the whiskers indicate the 5th and 95th percentiles. Means are represented by small squares. Friedman test, $\mathrm{p}<0.0001 .{ }^{+}$Different from the other conditions, Wilcoxon test. ed lower with MI-E alone than with the two techniques using MAC (table 2). Subjective cough effectiveness ratings were not significantly different between these last two techniques.

\section{Individual Analysis}

Among the 18 patients, 9 (No. 4-6, 9, 12-14, 17 and 18) exhibited mask pressure swings during mechanical exsufflation, with a transiently positive mask pressure (peak value $12,8,6,12,3,14,9,8$ and $3 \mathrm{~cm} \mathrm{H}_{2} \mathrm{O}$, respectively) due to the expiration produced by the combined cough effort and MAC. Figure 4 shows a representative example. This transient positive-pressure swing was not detected by the MI-E device manometer. The duration of the positive-pressure swing correlated significantly with ECT $\left(\mathrm{R}^{2}=0.75, \mathrm{p}<0.0001\right)$ and was consistently lower than the ECT (fig. 5).

PCF with IPPB + MAC was higher in the 9 patients who exhibited positive-pressure swings during mechanical exsufflation than in the other patients (fig. 6, in which these 9 patients are represented by dotted lines) and all of them had PCF values above 5 liters/s in this condition.

Among the 9 remaining patients who did not exhibit a transiently positive mask pressure during mechanical exsufflation, 8 patients had a PCF value below 5 liters/s when using IPPB + MAC, and only 3 achieved higher PCF values when using this condition compared with the conditions which included MI-E (fig. 6). Finally, all the patients who had a PCF value above 5 liters/s with IPPB + MAC had the highest PCF with this technique.
Fig. 4. Example of transient positive facemask pressure swing during mechanical exsufflation, an effect ascribable to the flow induced by the combined patient cough effort and MAC.

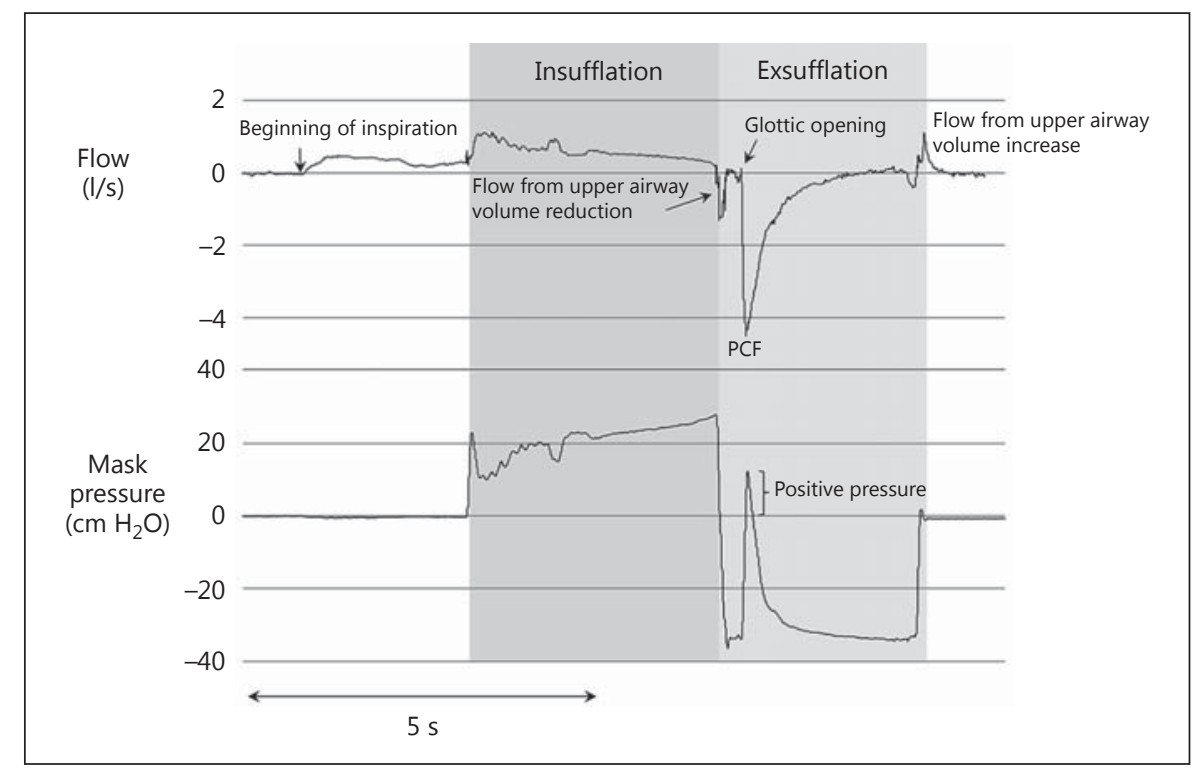

Three Cough-Augmentation Techniques in Neuromuscular Patients 


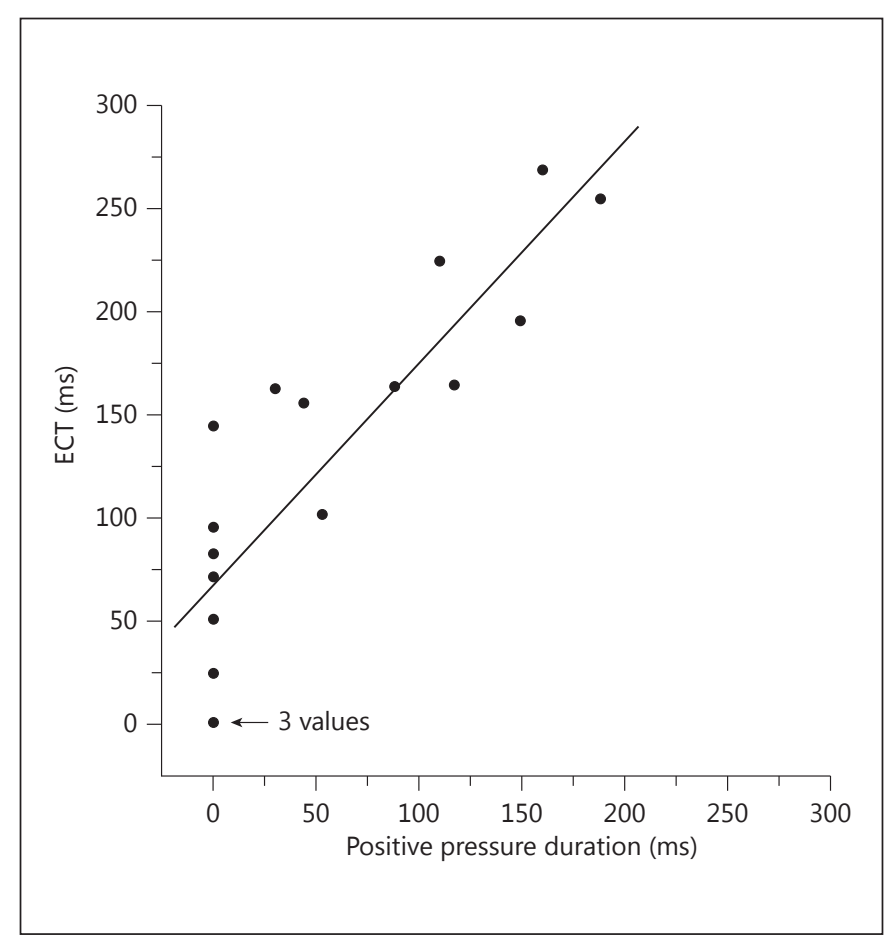

Fig. 5. Relationship between duration of the transient positivepressure due to the flow induced by the combined patient cough effort and MAC during mechanical exsufflation and the ECT defined as the time spent with a PCF greater than 3 liters/s. These two variables correlated significantly with each other (linear regression, $\left.\mathrm{R}^{2}=0.75, \mathrm{p}<0.0001\right)$.

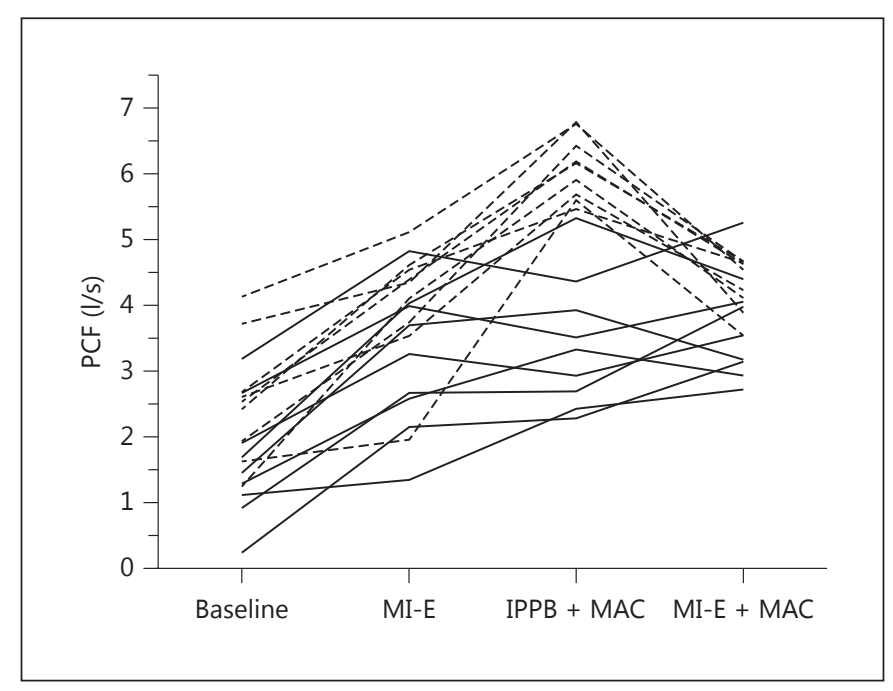

Fig. 6. Individual PCF values with the three cough-assist techniques: MI-E, IPPB + MAC and MI-E + MAC. The dotted lines represent patients in whom facemask pressure became transiently positive during mechanical exsufflation due to the flow induced by the combined patient cough effort and MAC.

\section{Discussion}

We report the first systematic comparison of MAC, mechanical exsufflation, and both combined, for cough assistance after maximal tolerated mechanical insufflation in patients with NMD. We found a significantly higher PCF with IPPB + MAC than with the other conditions (Friedman and Wilcoxon tests in the 18 patients). When analyzing individual results (fig. 6) we observed that, when PCF with IPPB + MAC was above 5 liters/s, it was systematically higher than with the other two techniques. Accordingly, in an earlier study which used similar mean expiratory pressure $\left(-40 \mathrm{~cm} \mathrm{H}_{2} \mathrm{O}\right)$ as in our study (mean expiratory pressure $=-38.2 \mathrm{~cm} \mathrm{H}_{2} \mathrm{O}$ ), but in patients with amyotrophic lateral sclerosis, when PCF was greater than 4 liters/s with inspiratory assistance and MAC, MI-E + MAC was not effective [19]. However, the conditions were different between both studies. Our patients were asked to cough forcefully during each technique, whereas the earlier study evaluated PCF generated by MI-E + MAC while patients were passive, in order to simulate severely advanced muscle weakness [19]. Moreover, most patients in the earlier study presented with severe bulbar dysfunction, and computed tomography showed upper airway collapse during the MI-E exsufflation cycle in the subset with PCF values lower than 2.7 liters/s during MI-E + MAC [19]. This upper airway collapse likely explained the lack of effectiveness of MI-E + MAC [19]. In our study, the 15 patients with baseline PCF values lower than 2.7 liters/s had PCF values above baseline during MI-E + MAC, which may result from the active patient participation in coughing and the absence of severe bulbar dysfunction. Although we did not exclude upper airway collapse during MI-E in our patients, we observed in 9 patients a transient positive-pressure swing that coincided with the PCF obtained during MAC. This reflects a high resistance of the apparatus during the early peak expiratory flow, which, instead of facilitating collapse, may help to keep the upper airway open at the beginning of the cough. On the other hand, the MI-E device and its circuitry constituted a load against PCF. In contrast to PCF, ECT was not significantly modified by the MI-E device, probably because the positive-pressure swing durations were shorter than ECT (fig. 6). Since the 9 patients who had a transient positive-pressure swing during cough were among the 10 with a PCF above 5 liters/s with IPPPB + MAC, our results suggest that MI-E may be without additional benefit when PCF with MAC or IPPB + MAC is above 5 liters/s. 
The choice of cough-assist technique is an important topic as they may play a key role in the management of acute respiratory failure episodes and invasive ventilation weaning in this fragile population. Maximal inspiratory pressure tolerated by the patients was higher with IPPB than with MI-E. This was probably due to the difference in inspiratory flow generated by the two devices, which was higher with MI-E. Nevertheless, despite this difference of maximal inspiratory pressure, the same IC was obtained with the three techniques. This may result from a decreased inspiratory effort during IPPB compared to MI-E, as we suspected during the trial. To decrease costs, we chose IPPB when MAC was used alone during the expiratory phase, as IPPB devices are about 5 times less costly than MI-E devices [17] and could be incorporated into ventilators in the future. Thus, IPPB + MAC would be simpler and less expensive than adding an MI-E device when inspiratory assistance produces sufficient cough assistance.

\section{Limits of the Study}

As in previous studies [26], none of our evaluations included clinical outcomes such as survival, frequency of exacerbations and hospitalization, or duration of hospital stay. Our study was limited to PCF, which is usually used [26] and which could predict cough efficiency. To improve the spirometric indices, we included the duration of PCF above 3 liters/s, but because this index was not previously used in the literature, we did not use it as a primary outcome measure. Interestingly, it was not different between IPPB + MAC and MI-E + MAC, suggesting that, in the end, both methods could have a similar effective- ness. Nevertheless, the less expensive cost of IPPB compared to MI-E should be taken in account in the choice of technique.

IPPB + MAC use could be considered as limited in a home setting given that it requires the cooperation and education of the caregivers, including the family. However, as suggested by Bach [7] and recommended by the 'High Health Authority' of the French government [29], families and caregivers have to learn cough techniques to improve patient cough performances at home and outside the medical context. That is why in our daily practice physiotherapists are used to teach MAC manoeuvers to families and caregivers. We did not evaluate IPPB alone because we previously studied this condition and observed that IPPB + MAC gave a higher PCF than either MAC alone or IPPB alone [16].

\section{Conclusions}

Adding MI-E to MAC may be deleterious or inefficient in NMD patients who can generate high PCF values with combined insufflation and MAC. In addition, insufflation with MAC is simpler and less expensive than MI-E and MAC. Patients with NMD should be evaluated on a case-by-case basis to determine which cough-assist technique is most beneficial.

\section{Acknowledgements}

We thank Daniel Isabey for helpful discussions about the results of this study.

\section{References}

$\checkmark 1$ Ambrosino N, Carpene N, Gherardi M: Chronic respiratory care for neuromuscular diseases in adults. Eur Respir J 2009;34:444451

-2 Bach JR, Saporito LR: Criteria for extubation and tracheostomy tube removal for patients with ventilatory failure: a different approach to weaning. Chest 1996;110:1566-1571.

$\checkmark 3$ Goncalves MR, Honrado T, Winck JC, Paiva JA: Effects of mechanical insufflation-exsufflation in preventing respiratory failure after extubation: a randomized controlled trial. Crit Care 2012;16:R48.

-4 Suarez AA, Pessolano FA, Monteiro SG, Ferreyra G, Capria ME, Mesa L, Dubrovsky A, De Vito EL: Peak flow and peak cough flow in the evaluation of expiratory muscle weakness and bulbar impairment in patients with neuromuscular disease. Am J Phys Med Rehabil 2002;81:506-511.

75 Boitano LJ: Management of airway clearance in neuromuscular disease. Respir Care 2006; 51:913-922, discussion 922-924.

6 6 Bott J, Blumenthal S, Buxton M, Ellum S, Falconer C, Garrod R, Harvey A, Hughes T, Lincoln M, Mikelsons C, Potter C, Pryor J, Rimington L, Sinfield F, Thompson C, Vaughn P, White J, British Thoracic Society Physiotherapy Guideline Development G: Guidelines for the physiotherapy management of the adult, medical, spontaneously breathing patient. Thorax 2009;64(suppl 1):i1-i51.

7 Bach JR: Mechanical insufflation-exsufflation: comparison of peak expiratory flows with manually assisted and unassisted coughing techniques. Chest 1993;104:1553-1562.

$>8$ Dail CW: 'Glossopharyngeal breathing' by paralyzed patients; a preliminary report. Calif Med 1951;75:217-218.

$>9$ Pryor JA: Physiotherapy for airway clearance in adults. Eur Respir J 1999;14:1418-1424.

10 Kang SW, Bach JR: Maximum insufflation capacity. Chest 2000;118:61-65.

-11 Bach JR, Mahajan K, Lipa B, Saporito L, Goncalves M, Komaroff E: Lung insufflation capacity in neuromuscular disease. Am J Phys Med Rehabil 2008;87:720-725.

-12 Simonds AK, Muntoni F, Heather S, Fielding S: Impact of nasal ventilation on survival in hypercapnic Duchenne muscular dystrophy. Thorax 1998;53:949-952.
Three Cough-Augmentation Techniques in Neuromuscular Patients 
13 Chatwin M, Ross E, Hart N, Nickol AH, Polkey MI, Simonds AK: Cough augmentation with mechanical insufflation/exsufflation in patients with neuromuscular weakness. Eur Respir J 2003;21:502-508.

14 American association for respiratory care: AARC clinical practice guideline: intermittent positive pressure breathing. Respir Care 1993;38:1189-1195.

15 Welch MA Jr, Shapiro BJ, Mercurio P, Wagner W, Hirayama G: Methods of intermittent positive pressure breathing. Chest 1980;78: 463-467.

16 Trebbia G, Lacombe M, Fermanian C, Falaize L, Lejaille M, Louis A, Devaux C, Raphael JC, Lofaso F: Cough determinants in patients with neuromuscular disease. Respir Physiol Neurobiol 2005; 146:291-300.

17 Dohna-Schwake C, Ragette R, Teschler H, Voit T, Mellies U: IPPB-assisted coughing in neuromuscular disorders. Pediatr Pulmonol 2006;41:551-557.

18 Sivasothy P, Brown L, Smith IE, Shneerson JM: Effect of manually assisted cough and mechanical insufflation on cough flow of normal subjects, patients with chronic obstructive pulmonary disease (COPD), and patients with respiratory muscle weakness. Thorax 2001;56:438-444.
9 Sancho J, Servera E, Diaz J, Marin J: Efficacy of mechanical insufflation-exsufflation in medically stable patients with amyotrophic lateral sclerosis. Chest 2004;125:1400-1405.

-20 Toussaint M, Boitano LJ, Gathot V, Steens M, Soudon P: Limits of effective cough-augmentation techniques in patients with neuromuscular disease. Respir Care 2009;54:359-366.

-21 Senent C, Golmard JL, Salachas F, Chiner E, Morelot-Panzini C, Meninger V, Lamouroux C, Similowski T, Gonzalez-Bermejo J: A comparison of assisted cough techniques in stable patients with severe respiratory insufficiency due to amyotrophic lateral sclerosis. Amyotroph Lateral Scler 2011;12:26-32.

22 Mustfa N, Aiello M, Lyall RA, Nikoletou D, Olivieri D, Leigh PN, Davidson AC, Polkey MI, Moxham J: Cough augmentation in amyotrophic lateral sclerosis. Neurology 2003;61: 1285-1287.

23 Official statement of the European Respiratory Society: Standardized lung function testing. Eur Respir J 1993;16(suppl):1-100.
24 Hart N, Polkey MI, Sharshar T, Falaize L, Fauroux B, Raphael JC, Lofaso F: Limitations of sniff nasal pressure in patients with severe neuromuscular weakness. J Neurol Neurosurg Psychiatry 2003;74:1685-1687.

25 Szeinberg A, Tabachnik E, Rashed N, McLaughlin FJ, England S, Bryan CA, Levison $\mathrm{H}$ : Cough capacity in patients with muscular dystrophy. Chest 1988;94:1232-1235.

26 Morrow B, Zampoli M, van Aswegen H, Argent A: Mechanical insufflation-exsufflation for people with neuromuscular disorders. Cochrane Database Syst Rev 2013;12:CD010044.

27 Miller MR, Hankinson J, Brusasco V, Burgos F, Casaburi R, Coates A, Crapo R, Enright P, van der Grinten CP, Gustafsson P, Jensen R, Johnson DC, MacIntyre N, McKay R, Navajas D, Pedersen OF, Pellegrino R, Viegi G, Wanger J, Force AET: Standardisation of spirometry. Eur Respir J 2005;26:319-338.

28 Aitken RC: Measurement of feelings using visual analogue scales. Proc R Soc Med 1969;62: 989-993.

29 Leger P, Paulus J: Recommendations of HAS: Practical issues in home non-invasive ventilation in patients with neuromuscular disease (in French). Rev Mal Respir 2006;23(4 suppl): 13S141-13S143. 